\title{
Space Resources Science
}

\section{A White Paper for the Planetary Sciences and Astrobiology Decadal Survey 2023-2032}

\author{
Dr. Leslie S. Gertsch \\ Missouri University of Science and Technology \\ Rolla, MO 65401
}

GertschL@mst.edu, 573-341-7278 


\section{Abstract}

Exploring space continuously rather than intermittently requires permanent, ongoing presence there. And that presence, whether human or robotic, requires that local in-space mineral resources be used effectively. In the next decade this will be supported most effectively by advancing the sciences involved in such use by, specifically, enabling basic resources science research alongside technology development, and improving demonstration requirements and facilities.

\section{Introduction}

The fundamental capabilities that have led to humans thriving on Earth are agriculture and mining. Both developed over millennia in relatively similar environments on Earth's surface. Both reflect the science understanding and engineering capabilities of the times. Neither can operate in space in the same way as on Earth. Current-art practices have to be changed.

We humans tend to ignore familiar activities, such as agriculture and mining, and focus on new ones, such as space exploration. We forget the ongoing innovation required to sustain mature industries in the excitement of developing new ones. This paper argues that this tendency must be actively resisted; the science of space resources is deep and profound and cannot be re-constituted ad hoc in space. Rather, its focused reinvigoration is necessary to enable and sustain planetary sciences and astrobiology through even better-guided space resources technology development than at present.

\section{Background}

Mineral resources science works toward comprehensive understanding of the fundamental processes that underlie successful resource utilization anywhere (on or off Earth). Stated another way, mineral resources engineering applies a broad range of sciences to the use of geologic materials to support humanity. The most obvious mineral resource sciences are economic geology ${ }^{1}$ and geometallurgy ${ }^{2}$, founded on physics (mechanics, electricity, and magnetism) and chemistry, but various types of mathematics (optimization, modeling and systems analysis, geostatistics, etc.) are important as well. Manufacturing science relies on the same three basic disciplines.

Mineral production evolves continuously, for several reasons. The mineral deposits on Earth that are amenable to extraction by current-practice techniques inevitably become rarer as they are used up. Simultaneously, demand for mineral products is increasing due to growing human population and its growing expectations for quality of life. It's an exponential demand growth curve. This drives innovation through economic levers. The thin profit margins of the most indemand nonfuel mineral materials - in decreasing order of value: crushed stone, cement, construction sand and gravel, and gold ${ }^{3}$ - force continual, relentless innovation under significant economic constraints ${ }^{4}$ (Figure 1 ). Current levels of mineral or manufacturing research cannot be expected to ramp up to the space resources challenges of returning to the Moon, exploring Mars, or protecting Earth from asteroid impact, without formal direction now. The enormous differences between Earth and space operational environments, and the subtly 
complex interplay of fundamental process in geologic materials, will seriously retard purely empirical approaches without improvements in space resources science.

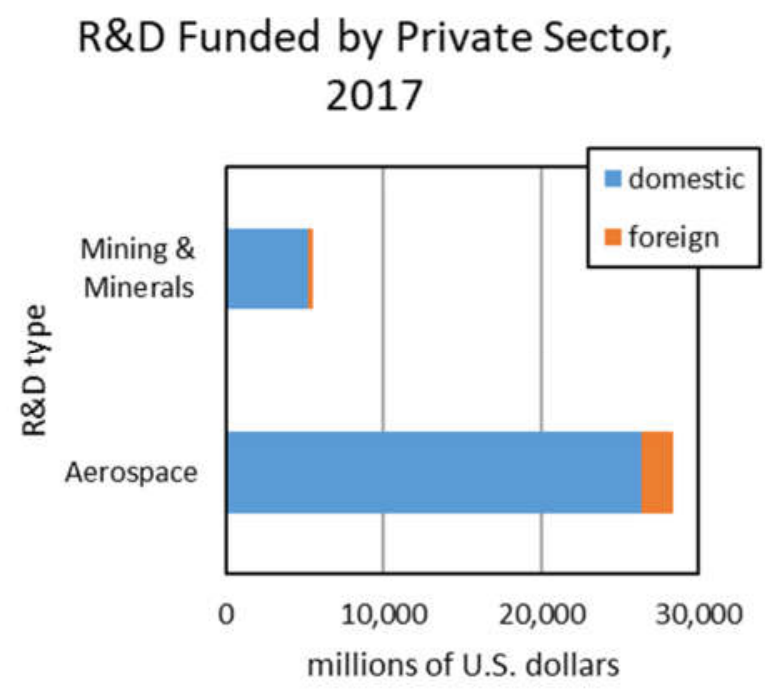

R\&D Funded by U.S. Government, 2018

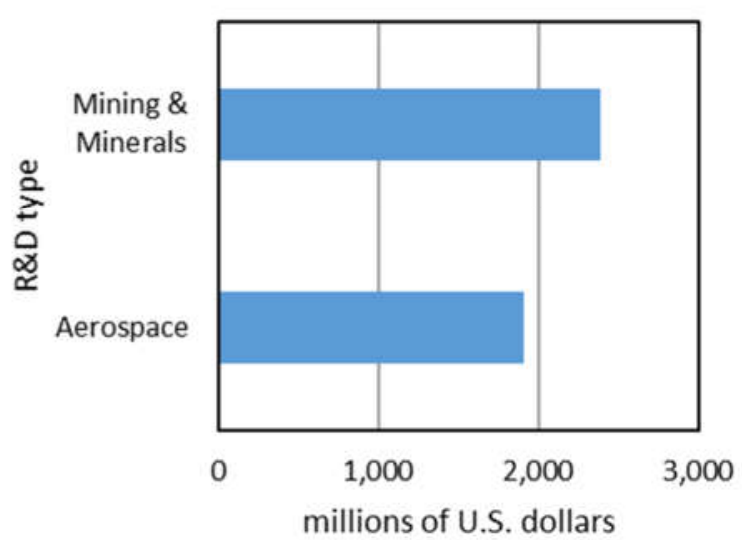

Figure 1. (Left) Expenditures in 2017 by domestic (blue) and foreign (orange) companies in the U.S. for mining and mineral-related (top) and aerospace-related (bottom) research. [5] (Right) U.S. government-funded research expenditures in 2018 in the same categories. Note the differences in dollar scales and year. [6]

No cut-and-dried mining or manufacturing technology is ready for export even to Mars, the most Earth-like planet, let alone to asteroids or icy moons. Indeed, the least noticed aspects of production practice are those that are limited to Earth operations, most notably the constant unidirectional pull of gravity, the thermal buffering of atmosphere, and the multiple useful properties of liquid water ${ }^{7}$.

Instead, what must be developed in the next decade is better fundamental understanding of the tasks necessary to produce useful things from minerals, in space:

- Prospect - Identify and locate deposits of geologic materials that are likely to contain the target material (element, mineral, mineral mixture) in some form.

- Mine-Get control of the raw material by removing it from where it occurs and transferring it to an engineered process stream.

- Process - Transform the raw material into a form amenable to being used for human purposes, i.e., feedstock.

- Manufacture or construct - Work the processed material into needed commodities, goods, and infrastructure.

These tasks are often broken down further, but at the unit operations level ${ }^{8}$ they begin to reflect the constraints of the operational environment. The full trade space for extracting 
mineral materials is much broader than Earth-constrained approaches address; however, that subset can be built upon. Mineral production and manufacturing in space may not take advantage of the entire trade space either, but they will shift and expand it significantly beyond previous human experience. We can prepare by taking maximum advantage of that experience.

Experience in soil and rock engineering has revealed that fundamental natural processes interact in extremely complex ways even in our most familiar environments, producing aggregate dynamic behaviors that are not reliably predictable from first principles of the basic sciences. The very unfamiliar environments of non-Earth locations will make these even less predictable, if for no other reason than the lack of sufficient operational data.

Successfully transferring production practices from Earth to space will be extremely difficult. Even the most automated deep mine with its advanced technologies ultimately is based on physical human capabilities; the predilection to work with granular solids is one example. Working in space will stretch that link further, and may eventually break it, but not during the coming decade. Human history contains numerous examples where adapting practices between terrestrial environments was not as easy or as direct as originally thought (e.g., the Dust Bowl resulted largely from the belief - supported by available data at the time ${ }^{9}$ - that "rain follows the plow").

Thus it is crucial that the foundation of these tasks not be neglected in the rush to develop space resources technology. Operational data must be gathered as much and as soon as possible, to calibrate and inform predictions from theoretical considerations and models.

Neither space resources nor ISRU were mentioned in the 2003 decadal survey ${ }^{10}$. Sample gathering/ handling and autonomous mobility technology developments were discussed (graded D and C, respectively) in the 2007 review ${ }^{10}$, but mining and manufacturing comprise significantly tasks more than those two. The 2011 decadal survey ${ }^{10}$ touched very briefly on space resources from the Moon and Mars and as an overlapping interest between NASA's science and exploration directorates; several white papers discussed various aspects. By 2017, lunar polar volatiles and the Lunar Resource Prospector (LRO) were featured in a brief review of progress ${ }^{10}$, and the 2018 more comprehensive review ${ }^{10}$ noticed space resources research as part of the Origins, Spectral Interpretation, Resource Identification, Security, Regolith Explorer (OSIRIS-REx) mission, and the Mars Oxygen In-Situ Resource Utilization Experiment (MOXIE) on the Mars 2020 Perseverance rover to be launched next month.

Space resources technology development is supported mainly through the NASA Small Business Innovation Research (SBIR) program, as reviewed by [11,12], though the projects mentioned above and the Volatiles Investigating Polar Exploration Rover (VIPER, descended from Lunar Resource Prospector) are mission-oriented. This is predicated correctly on the need to demonstrate ISRU system technologies as early as possible "so that mission planners will have the confidence to include insitu capabilities in the baseline mission design"11. However, emphasizing technology development too far ahead of fundamental understanding may lead to wasted time and effort if the science and the technology are not properly coupled and tested. 


\section{Critical Knowledge Gaps}

The most effective approach to enabling space resources utilization starts with engaging the basic and applied research already in progress and filling the gaps that still exist.

\section{Critical Gap 1. Lack of a well-founded mining and manufacturing architecture.}

The default plan for producing water on the Moon and on Mars is patterned after terrestrial production of industrial minerals such as clay, sand, and gravel, without sufficient consideration not just of the environmental constraints, but also unexpected process subtleties that on Earth are solved with extensive empirical testing. One example of both problems is uncontrolled phase changes at sensitive points in a process. This will be especially important in automated operations such as discussed by [13 and others].

This gap is best remedied not by an immediate program focused narrowly on developing "the best" system, or by continuing the SBIR approach alone. Present data and understanding are not sufficient for either. It should begin instead with an in-depth review of applicable fundamental knowledge, conditioned by the effects of environmental constraints on past and present Earth technologies. The findings then should be followed up with specific research using SBIR and science instrument-development programs ${ }^{14}$ - to fill the gaps revealed thereby, ranked according to their urgency (a metric incorporating likelihood of need, depth of ignorance, risk of failure, and cost of failure).

Even prior to such a comprehensive study, the need for some lines of inquiry is apparent:

- An understanding of the natural processes that concentrate desired minerals or materials in specific locations (i.e., mineral deposits) in space. This would inform prospecting at all levels, for all target materials and sensing techniques, as well as production scheduling and mine layouts.

For example, the creation of mineral deposits by surface water flow has been studied in detail because it is common on Earth's surface and important for the formation of placers and sediment-hosted deposits. The dynamics of impacts, a very different process that is much more common off Earth, lead to different segregation trends.

- Illustrative examples of direct translations of current practice that will be needed during the next decade:

O Comminution ${ }^{15}$. Though at first look it appears unnecessary for processing regolith, given regolith's extreme fineness, that determination actually depends on the size fraction in which the target materials are found, and whether recovery would be improved by further size reduction or, possibly, agglomeration. Nanophase iron, for example, occurs in lunar regolith within the rims of certain particles ${ }^{16}$ and thus the finest size fraction is potentially the richest ore for metallic iron. However, fines are the most difficult size fraction to handle.

- Physical separation of solid particles by differences in physical, chemical, or surface properties of ore versus waste can be extrapolated to only a limited extent from Earth to space. The behavior of granular vs. molecular vs. mixed materials in vacuum vs. 
intermittent atmosphere (batch processes) vs. full-time atmosphere (continuous processes) is understood imperfectly even in Earth applications, making transferal even more difficult. State-of-the-practice development of new processes is highly empirical.

- Selected example of developments needed in space for this and subsequent decades:

- Ore-waste separation in vacuum, microgravity, or fluctuating gravity consists of one set of principles if the ore and waste are solid particles, but an entirely different set if the ore and waste are in other forms, such as vapor ${ }^{17,18}$.

\section{Critical Gap 2. Insufficient experimental and demonstration capacity in Earth-analog and in situ settings appropriate for utilizing space resources.}

Testing and demonstration matrices should be comprehensive enough to permit the identification of trade-space subsets with sufficient promise for further development. The large number of natural phenomena that must interact in predictable, controllable ways for the success of a process, especially a new one, means that manageable trade space subsets may be restricted to relatively narrow classes of space bodies. It will be extremely difficult to test or demonstrate technological capabilities for any of these bodies adequately on Earth.

Accordingly, a significant amount of such testing should be carried out in situ as well as in Earthanalog environments. The cost and logistics transition points between in situ and analog will have to be evaluated. The Artemis program will be a valuable enabler, not just for the Moon but also for early-stage experience in space resources production activities.

\section{Roadmap for the Next Decade and Beyond}

The most effective approach to fill these two knowledge gaps is to establish a comprehensive set of research programs to review the basic sciences of space resources engineering, to illuminate and inform productive pathways using the SBIR and instrument development programs already in play. The funding for these programs could be shared with the National Science Foundation along with other U.S. government agencies, international partners, professional societies ${ }^{19}$, and industry trade groups. The Artemis program provides a natural locus for initial work; much of the basic research for and near the Moon would also be applicable to supporting work at other planetary science and astrobiology destinations.

Additionally, the science of space resources, like all other science and engineering endeavors, when reaching its full potential draws on broad human as well as technical perspectives. Studies of scientific teams have repeatedly demonstrated the importance of an integrated approach, where team members with diverse expertise develop synergies between their specialties and resources that result in an end product that adds up to more than the sum of its parts ${ }^{20}$. Sociological studies have demonstrated that groups that foster strong connections across sub-units are more innovative [21-23] with higher impact outcomes that endure [23,24]. Even the mining industry is pragmatic enough to overcome its natural conservatism and work to change long-held divisive practices [25]. The decadal survey should consider the state of the profession and the issues of equity, diversity, inclusion, and accessibility - not as separable issues, but as critical steps on the pathway to enabling the science of space resources, and thus the goals of planetary science and astrobiology. Background information on the current lack of 
diversity in these communities and specific actionable and practical recommendations can be found in several white papers being submitted to this Decadal Survey.

\section{Summary}

Mineral resources sourced from space and used to manufacture commodities in space would sustain planetary science and astrobiology indefinitely. Such activities will be more likely, more robust, and will occur sooner, with appropriate in-depth space resources science preparation than without it.

\section{References and Notes}

1. "The scientific study of the Earth's sources of mineral raw materials and the practical application of the acquired knowledge.": Pohl, W.L., 2011. Economic Geology, Principles and Practice: Metals, Minerals, Coal and Hydrocarbons - an Introduction to Formation and Sustainable Exploitation of Mineral Deposits. 663 Pages, Wiley-Blackwell, Oxford.

2. Lishchuk, V., Koch, P.H., Ghorbani, Y. and Butcher, A.R., 2020. Towards integrated geometallurgical approach: Critical review of current practices and future trends. Minerals Engineering, 145, p.106072.

3. U.S. Geological Survey, 2020 (https://www.usgs.gov/news/us-mine-production-increasingestimated-value-863-billion-minerals)

4. "The mining and metals industry ... spends less than $1 \%$ of its revenues on R\&D.": Filippou, D. and M.G. King, 2011. R\&D prospects in the mining and metals industry. Resources Policy, 36, p.276-284.

5. NSF, 2019 (https://www.nsf.gov/statistics/2019/nsf19326/)

6. NSF, 2018 (https://ncsesdata.nsf.gov/fedfunds/2018/html/ffs18-dt-tab017.html)

7. Powerful solvent, poor electrolyte, high heat capacity, expands on freezing, very high surface tension, high viscosity, high wetting ability: B. Wills, 1997. Mineral Processing Technology, $6^{\text {th }}$ ed., Butterworth-Heinemann, $486 \mathrm{pp}$.

8. Fragmentation, beneficiation, comminution, separation, transportation: P. Darling (editor), 2011. SME Mining Engineering Handbook, $3^{\text {rd }}$ ed, Soc for Mining, Metallurgy, \& Exploration Inc., 1840pp.

9. J. Welty et al. Does soil moisture affect warm season precipitation over the Southern Great Plains?, Geophysical Research Letters (2018). DOI: 10.1029/2018GL078598 https://agupubs.onlinelibrary.wiley.com/doi/epdf/10.1029/2018GL078598

10. Cited decadal surveys and reviews available at https://www.nationalacademies.org/ourwork/planetary-science-and-astrobiology-decadal-survey-2023-2032.

11. D. Linne et al. 2017. Overview of NASA technology development for in-situ resource utilization (ISRU). 68th International Astronautical Congress, Sep 25-29, 2017, Adelaide, Australia. https://ntrs.nasa.gov/search.jsp? R=20180000407

12. S.O. Starr et al. 2020. Mars in situ resource utilization: a review. Planetary and Space Science 182, paper 104824.

13. B.H. Wilcox et al., 2019, March. Autonomous Mars ISRU Robotic Excavation: Characteristics and Performance Targets. In 2019 IEEE Aerospace Conference (pp. 1-19). IEEE. 
14. Planetary Instrument Concepts for the Advancement of Solar System Observations (PICASSO); Maturation of Instruments for Solar System Exploration (MatISSE); and Development and Advancement of Lunar Instrumentation (DALI)

15. Solid particle size reduction, also called crushing and grinding - the most energy-intensive aspect of mineral production: R.C. Dunne et al, editors. 2019. SME Mineral Processing \& Extractive Metallurgy Handbook, Soc for Mining, Metallurgy, \& Exploration Inc., 2203pp.

16. S. Noble et al., 2005. Evidence of space weathering in regolith breccias I: Lunar regolith breccias. Meteoritics \& Planetary Science, 40(3), pp.397-408.

17. Sowers, G.F. and Dreyer, C.B., 2019. Ice mining in lunar permanently shadowed regions. New Space, 7(4), pp.235-244.

18. Sercel, J.C., Dreyer, C.B., Abbud-Madrid, A., Britt, D., Jedicke, R., Gertsch, L. and Love, S.G., 2016. A coordinated research program to develop the technology to optical mine asteroids. In Earth and Space 2016: Engineering for Extreme Environments (pp. 507-522). Reston, VA: American Society of Civil Engineers.

19. American Institute of Mining, Metallurgical, and Petroleum Engineering; American Society of Mechanical Engineers; American Society of Civil Engineers; Institute of Electrical and Electronics Engineers; American Society of Chemical Engineers.

20. Balakrishan et al. 2011 (https://dl.acm.org/doi/10.1145/1958824.1958905)

21. Burt 2004 (https://www.journals.uchicago.edu/doi/10.1086/421787)

22. Powell et al. 1996 (https://www.jstor.org/stable/2393988?origin=crossref\&seq=1)

23. de Vaan et al. 2015 (https://www.jstor.org/stable/10.1086/681213?seq=1);

24. Curral et al. 2001 (https://www.tandfonline.com/doi/abs/10.1080/13594320143000627)

25. Ndlovu 2018 (SAIMM President's Editorial: Diversity and Inclusion in the Minerals Industry), Jour Southern African Institute of Mining \& Metallurgy, Vol 118, July, page v. 